\title{
Genetics Corner: Trichothiodystrophy 1 Causes Neutropenia in an Infant with Congenital ichthyosis and Brittle Hair
}

Robin Dawn Clark, MD and Subhadra Ramaanthan, MSc, MS

\section{Clinical history:}

A 10-month old male infant was referred for genetic evaluation for trichothiodystrophy 1 .

He was delivered at $\sim 32$ weeks' gestation by $\mathrm{C}$-section when his 23-year old G2 P1-->2 mother developed HELLP syndrome. His prenatal course had been complicated by IUGR and decreased fetal movements. Birth weight: 1474 grams (17 th $\%$ ile). Birth length: $41.9 \mathrm{~cm}$ (33 $\%$ ile). Apgar scores were 9 and 9 at 1 and 5 minutes, respectively. He had taut, shiny skin on his upper and lower extremities at birth, resembling collodion, which peeled during resuscitation. He was transferred from the birth hospital to the NICU at a nearby tertiary care center because of congenital ichthyosis, left eyelid fusion, and right cryptorchidism. His CBC and differential were normal.

At 18 days of age, the results of a rapid whole genome sequencing test identified biallelic variants in ERCC2 (or XPD)

c.2164C>T (p.Arg722Trp): pathogenic, paternally inherited

c.5+5G>A: a splicing variant of uncertain significance, maternally inherited

The infant was discharged on day 23 of life with a diagnosis of trichothiodystrophy-1.

At ten months of age, he was in generally good health. His mother had rescheduled his genetics clinic visit the previous month, and she had no particular concerns. She was satisfied that his "skin condition" was being managed and was not severe. He had a follow up (video) appointment with a dermatologist at six months of age. An ophthalmology evaluation revealed dry eyes but no cataracts. An otolaryngologist had seen him for recurrent impacted cerumen.

\section{Genetic evaluation:}

The infant had been mostly at home without much contact outside his immediate family because of the coronavirus restrictions. He had a history of one prior febrile illness with symptoms of a cold lasting about two weeks; he recovered but still had a persistent cough. He babbled and cooed. He had good eye contact, a social smile, and turned to his name. His mother reported that his developmental progress was "normal," but at ten months of age, he could only maintain a seated position for a few seconds.

The family history was noncontributory. The non-consanguineous parents, mother, age 24, and father, age 25, were of Mexican ancestry. They had one other child, a healthy 4-year old boy.

On physical examination, the growth parameters were poor for a 10 -month-old male. Weight $<1 \%$ ile $(Z=-2.47)$. Length $<1 \%$ ile $(Z=-3.45)$, BMI $16.27 \mathrm{~kg} / \mathrm{m}^{2}, 30 \%$ ile $(Z=-0.54)$. The baby was socially aware, interactive, and in no distress. He had deep-set eyes, down-slanting palpebral fissures, and bilateral epicanthal folds. There were sparse eyebrows and eyelashes (Figure 1). The scalp hair was sparse (Figure 2) with thick, waxy flakes and scales on the scalp. He had patchy areas of ichthyosis, mostly on the trunk and antecubital fossa. He had shiny skin on his palms, thin, dystrophic nails (toes>fingers), and shallow, short, concave nails.

The geneticist referred him to Pediatric Hematology and Pediatric Immunology, recommended RSV vaccination, and ordered an absolute neutrophil count (ANC). He had neutropenia: WBC 5.2, hemoglobin 12.8, platelets 312, ANC 0.4 (normal range 2.2-9.2 $\mathrm{bil} / \mathrm{L}$ ), but the ANC had normalized two weeks later at 6.6 .

At 11 months of age, he was hospitalized briefly for neutropenia (ANC 0.6), dry cough, and fever to 101.7 degrees without a documented source of infection (cultures were negative). The source of the infection was presumed to be viral. His differential had lymphocyte predominance without excess bands. His growth parameters then were still generally small for his age: $\mathrm{Ht} 70.5 \mathrm{~cm}, 2 \%$ ile $(Z=$ -2.10), Wt $7.11 \mathrm{~kg},<1 \%$ ile ( $Z=-2.71)$, HC $44 \mathrm{~cm}, 6$ \%ile $(Z=-1.55)$, BMI $14.31 \mathrm{~kg} / \mathrm{m}^{2} 2 \%$ ile $(Z=-2.09)$. At 13 months of age, he had an in-person visit with the pediatric dermatologist who documented tiger-tail banding on polarized trichoscopy (Figure 3).

"ERCC2 is a protein that acts as a DNA helicase in transcriptioncoupled nucleotide excision repair and phosphorylation of nuclear receptors. Cells use nucleotide excision repair to fix damaged DNA, including damage from ultraviolet radiation."

\section{Assessment and counseling:}

ERCC2 is a protein that acts as a DNA helicase in transcriptioncoupled nucleotide excision repair and phosphorylation of nuclear receptors. Cells use nucleotide excision repair to fix damaged DNA, including damage from ultraviolet radiation. Pathogenic variants in ERCC2 (XPD) are associated with a group of autosomal recessive disorders, including trichothiodystrophy (TTD) with sulfur-deficient brittle hair and developmental abnormalities but without skin cancer, xeroderma pigmentosum (XP) with pigmentary abnormalities and increased skin cancer, XP/TTD with combined

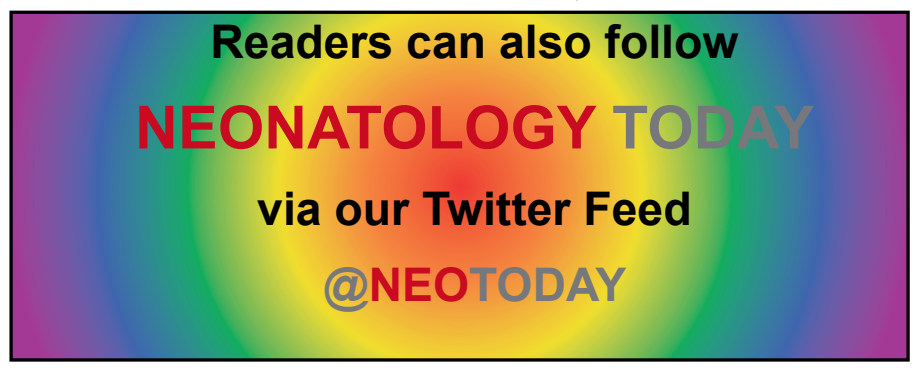


features that include skin cancer, and Cockayne syndrome, a rare premature aging syndrome that causes cutaneous photosensitivity and "cachectic dwarfism".

Signs and symptoms of TTD vary widely and include ichthyosis, abnormal fingernails and toenails, developmental delays, intellectual disability, dysmyelination, and cerebral atrophy. Some patients with neurological abnormalities are described to have an outgoing, sociable personality), delayed growth, short stature, dry eye, microcornea, nystagmus, congenital cataracts, neutropenia,

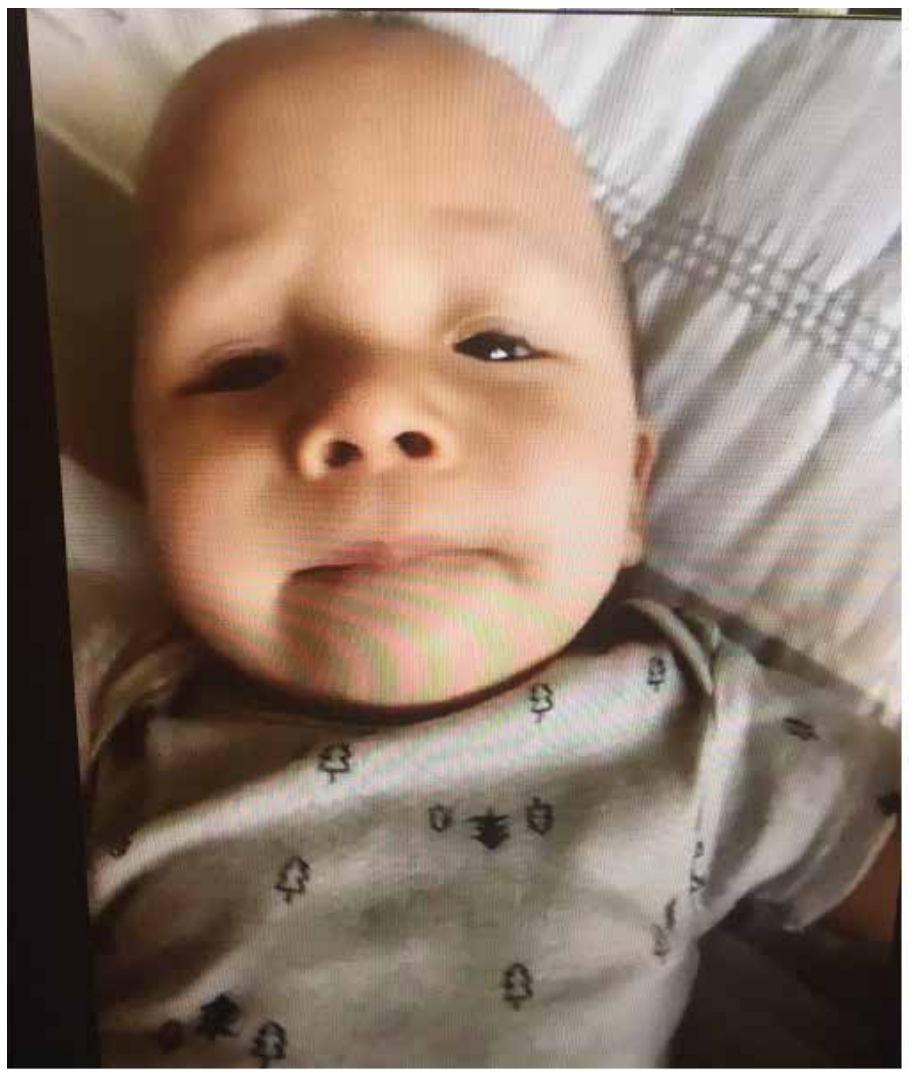

Figure 1: This infant with trichothiodystrophy has sparse hair and eyebrows, short and down-slanting palpebral fissures and deep $=$ set eyes

The only worldwide monthly publication
exclusively serving Pediatric and Adult
Cardiologists that focus on Congenital/
CONGENITAL
CARDIOLOGY
TORAY $\quad \begin{aligned} & \text { Cardiothoracic Surgeons. } \\ & \text { Free on the Home Page }\end{aligned}$




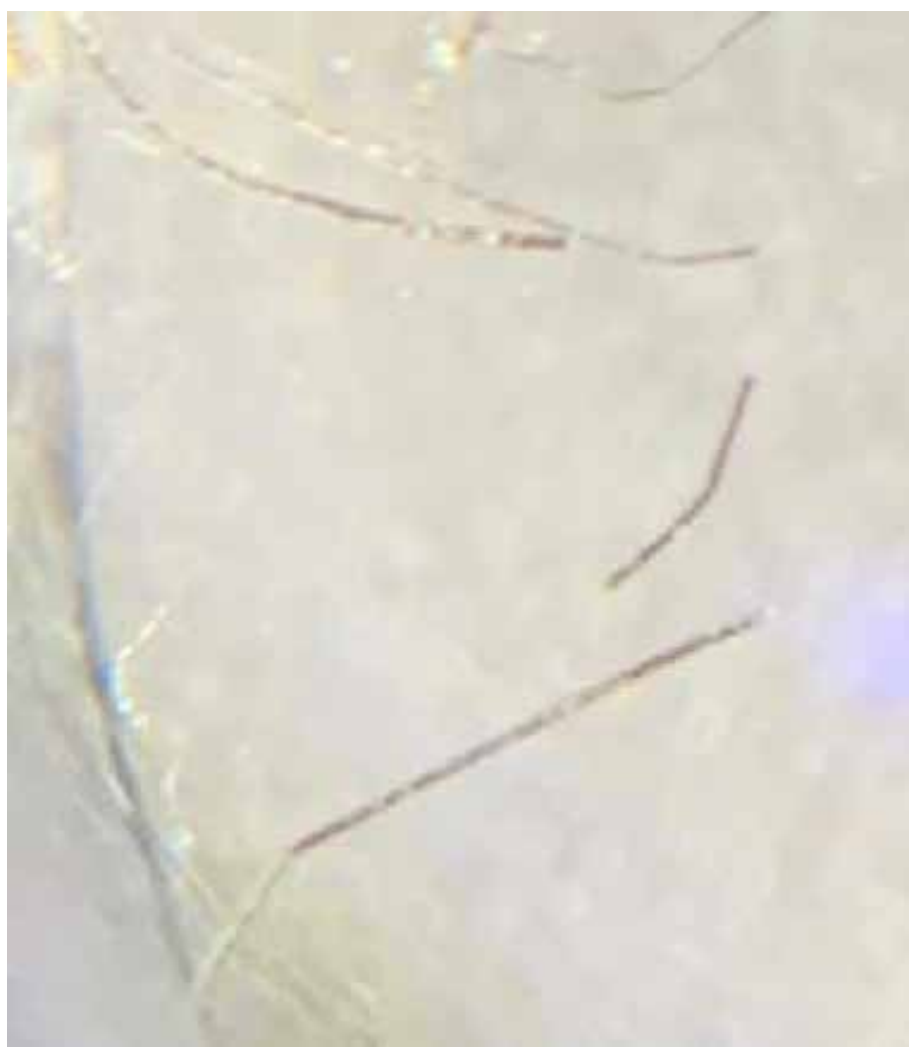

Figure 3: Tiger tail banding is evident on this polarized microscopic view of hair from this patient with trichothiodystrophy.

Tamura and associates (2011) found a high risk of pregnancy and neonatal complications in their cohort of 27 TTD-associated pregnancies in 23 mothers. There were pregnancy complications in 81\%: $56 \%$ had a preterm delivery, $30 \%$ had preeclampsia, $19 \%$ had placental abnormalities, $11 \%$ had HELLP syndrome, and $4 \%$ had an emergency c-section for fetal distress, while $44 \%$ had two or more complications. Only $19 \%$ of the pregnancies delivered at term without complications. Eight of the ten pregnancies tested had multiple abnormal screening markers, including elevated human chorionic gonadotrophin levels. Eighty-five percent of the neonates had complications: $70 \%$ were low birth weight $(<2500 \mathrm{~g})$, $35 \%$ had birth weight $<10^{\text {th }}$ centile for gestational age, $70 \%$ had NICU admission, $67 \%$ had a collodion membrane, and $31 \%$ of the 16 males had cryptorchidism. Cataracts were present in $54 \%$ of the TTD patients examined.

Although the diagnosis of this rare disease, trichothiodystrophy, was made quickly in this baby, he did not fully benefit from having an early diagnosis in the newborn period. He was discharged home from the NICU shortly after the diagnosis was made, and the focus of his subsequent care was on treating his ichthyosis, which was felt to be the major problem of his disorder. The mildness of his skin problems may have falsely reassured his family and his care team. The primary threat to his health was neutropenia and a high risk of infection; these were not appreciated until we alerted his care team. As rapid whole-genome sequencing becomes more available, neonatologists will have to rise to the challenge to realize the benefits and care coordination of early diagnoses for their patients.

\section{Practical applications:}

1. Understand that the benefits of a rapid genome sequencing test in the neonatal period may not be fully realized without careful phenotyping and coordinated multispecialty follow-up

2. Appreciate that pathogenic variants in one gene can cause several disorders.

3. Realize that trichothiodystrophy poses severe risks of neutropenia, infection, and increased mortality for affected infants. Offer RSV immunization to infants with trichothiodystrophy and follow for neutropenia

4. Recognize that HELLP syndrome in the mother can be a sign of a genetic disorder, such as trichothiodystrophy, in the fetus.

\section{References:}

1. Tamura D, Merideth M, DiGiovanna JJ, et al. High-risk pregnancy and neonatal complications in the DNA repair and transcription disorder trichothiodystrophy: report of 27 affected pregnancies. Prenat Diagn. 2011 Nov;31(11):104653. PMID: 21800331

2. Faghri S, Tamura D, Kraemer KH, Digiovanna JJ. Trichothiodystrophy: a systematic review of 112 published cases characterizes a wide spectrum of clinical manifestations. $J$ Med Genet. 2008 Oct;45(10):609-21. PMID: 18603627

3. Randall G, Kraemer KH, Pugh J, et al. Mortality-associated immunological abnormalities in trichothiodystrophy: correlation of reduced levels of immunoglobulin and neutrophils with poor patient survival. Br J Haematol. 2019 May;185(4):752754. PMID: 30334570

4. Zhou X, Khan, SG, Tamura D, et al. Abnormal XPD-induced nuclear receptor transactivation in DNA repair disorders: trichothiodystrophy and xeroderma pigmentosum. Eur J Hum Genet. 2013;21:831-837. PMID: 23232694

Disclosures: The authors have no relevant disclosures.

NT

NEONATOLOGY TODAY is interested in publishing manuscripts from Neonatologists, Fellows, NNPs and those involved in caring for neonates on case studies, research results, hospital news, meeting announcements, and other pertinent topics. Please submit your manuscript to: LomaLindaPublishingCompany@gmail.com 


\section{Corresponding Author}

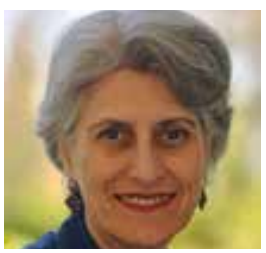

Robin Clark, MD

Professor, Pediatrics

Loma Linda University School of Medicine

Division of Genetics

Department of Pediatrics

Email rclark@llu.edu

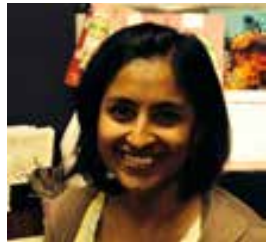

Subhadra (Subha) Ramanathan, M.Sc., M.S.

Licensed and Certified Genetic Counselor

Assistant Professor, Pediatrics

Loma Linda University Health

2195 Club Center Drive, Ste A

San Bernardino, CA 92408

SRamanathan@llu.edu

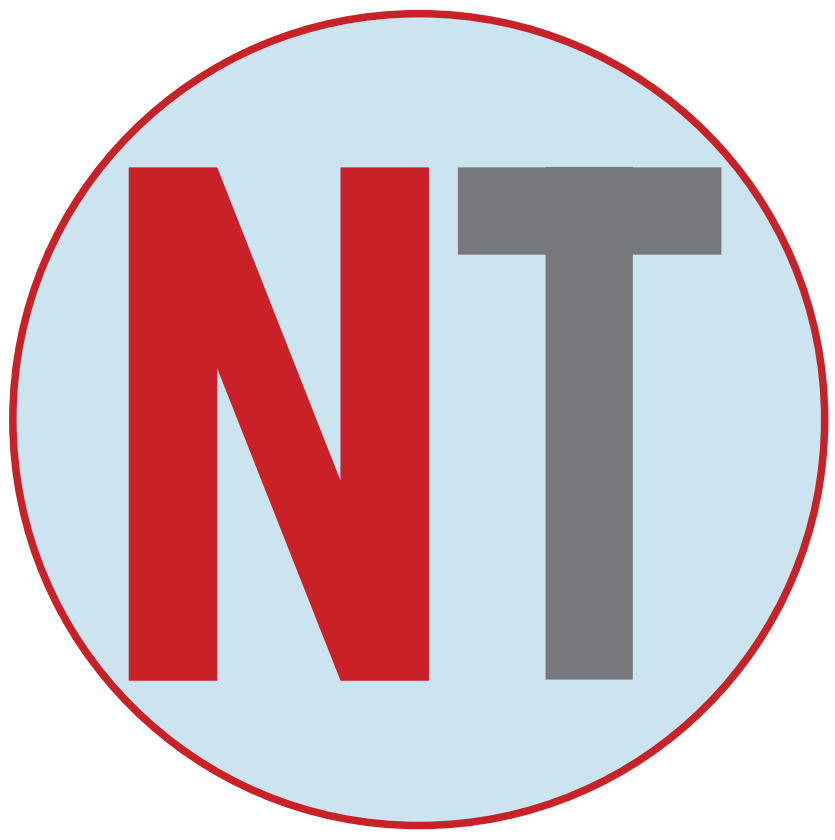

\section{OPIOIDS and NAS}

When reporting on mothers, babies,

and substance use

\section{LANGUAGE MATTERS}

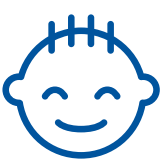

I am not an addict.

I was exposed to substances in utero.

I am not addicted. Addiction is a set of behaviors associated with having a Substance Use Disorder (SUD).

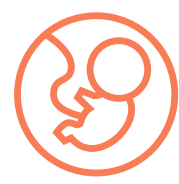

\section{I was exposed to opioids.}

While I was in the womb my mother and I shared a blood supply. I was exposed to the medications and substances she used. I may have become physiologically dependent on some of those substances.

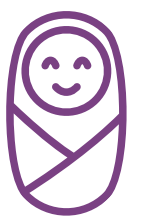

\section{NAS is a temporary and} treatable condition.

There are evidence-based pharmacological and non-pharmacological treatments for Neonatal Abstinence Syndrome.

\section{My mother may have a SUD.}

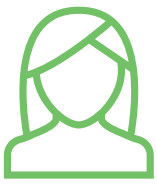

She might be receiving Medication-Assisted Treatment (MAT). My NAS may be a side effect of her appropriate medical care. It is not evidence of abuse or mistreatment.

\section{My potential is limitless.}

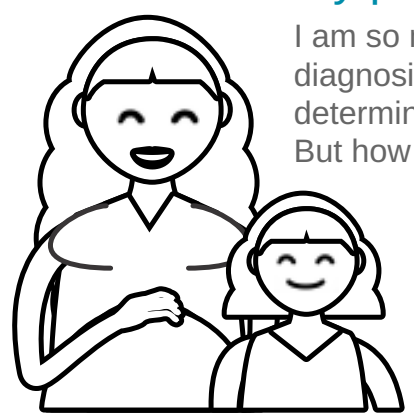

am so much more than my NAS diagnosis. My drug exposure will not my long-term outcomes. invest in my family's health and wellbeing by supporting Medicaid and Early Childhood Education you can expect that I will do as well as any of my peers!

Learn more about

Neonatal Abstinence Syndrome at www.nationalperinatal.org 